that each can be supported by one hemisphere or the other.

LAURENT COHEN
PHILIPPE RÉMY
ANNE LEROY
CHRISTIAN GENY
JEAN-DENIS DEGOS
Clinique des Maladies du Systeme Nerveux,
$\star$ Hôpital de la Salpétriere,
Paris,
Service de Neurologie, Hôpital Henri Mondor,
Créteil,
France

Correspondence to: $\mathrm{L}$ Cohen, Clinique des Maladies du Système Nerveux, Hôpital de la Salpétrière, 47 Bd de l'Hôpital, 75651 Paris Cedex 13 France.

1 Gross H, Kaltenbäck E. Die Anosognosie. Wiener Zeitschrift für Nervenheilkund
1955;11:374-418.

2 Cutting J. Study of anosognosia. J Neurol, Neurosurg Psychiatry 1978;41:548-55.

3 Bisiach E, Vallar G, Perani D, Papagno C, Bert A. Unawareness of disease following lesions of the right hemisphere: anosognosia for hemiplegia and anosognosia for hemianopia. Neuropsychologia 1986;24:471-82.

4 Hécaen H. Introduction à la neuropsychologie. Larousse: Paris, 1972.

5 Heilman KM, Watson RT, Valenstein E. Neglect and related disorders. In: Heilman $\mathrm{KM}$, Valenstein E, eds. Clinical neuropsychology. New York: Oxford University Press, 1985.

6 Ross ED. The aprosodias: Functional-anatomic organisation of the affective components of language in the right hemisphere. Arch Neurol 1951;38:561-9.

7 Zatorre RJ. Musical perception and cerebral function. a critical review. Music Perception 184;2:196-221.
8 Dronkers NF, Knight RT. Right-sided neglect in a left-hander: Evidence for reversed hemiin a left-hander: Evidence for reversed hemispheric specialisation of attention
Neuropsychologia 1988;27:729-35.

9 Cambier J, Masson M, Guillot M, Robine B. Négligence droite avec hémiasomatognosie, confusion mentale, apraxie et agraphie sans aphasie. Revue Neurologique 1985;141:802-6.

10 Hermann G, Pötzl O. UberAgraphie und ihre lokaldiagnostischen Beziehungen. S Karger: Berlin, 1926.

11 Hécaen H, Sauguet J. Cerebral dominance in left-handed subjects. Cortex 1971;7:19-48.

12 Rasmussen T, Milner B. Clinical and surgica studies of the cerebral speech areas in man. In: Zulch KJ, Creutzfeldt O, Galbraith GC, Zulch KJ, Creutzfeldt O, Galbraith GC, eds. isation. Heidelberg: Springer, 1975.

13 Geschwind N, Galaburda AM. Cerebral lateralisation. Biological mechanisms, associations, and pathology: 1. A hypothesis and a program and pathology: 1. A hypothesis and a program
for research. Arch Neurol 1985;42:428-59.

\section{Pure sensory stroke due to midbrain haemorrhage}

After reading the interesting case reported by Azouvi $e t$ al,${ }^{1}$ we would like to report a similar case, but in our patient the underlying disease was a cavernous angioma.

A 42 year old woman was admitted to our hospital because of a mild occipital pain, and dysaesthesia in the left part of her body. Neurological examination showed a fully oriented patient, loss of touch and pain sensations then involved the entire left side of her body, including the face. Vibration and position sensations were normal as were motor and cerebellar functions. Tendon jerks were symmetrical and plantar responses were flexor. Laboratory examinations, ECG and chest radiographs were normal. A CT showed a haematoma in the right dorsal and lateral aspect of the pons. An arteriographic study of both vertebral arteries showed no abnormalities. The neurological disorder resolved within three months. An MRI performed three months later revealed a hypodensity, of $0.8 \times 1.8 \mathrm{~cm}$ diameter, in the right dorsal and lateral aspect of the pons, suggesting a cavernous angioma (fig).

Since the first description in $1977,{ }^{2}$ only eight cases of haemorrhagic pure sensory stroke (PSS) have been described. All of them were secondary to small haematomas in the thalamus, internal capsule or pons. ${ }^{1}$ As far as we know, this is the first case of haemorrhagic PSS secondary to cavernous angioma located in the pons. In our patient, as in the one reported by Azouvi et al, ${ }^{1}$ the damage was restricted to the right dorsal spinothalamic tract without involving the medial lemniscus. We agree with the authors that smal haematomas located on the sensory pathways, before they reach the thalamus, can produce partial PSS. MRI is useful in detecting vascular malformations, even when, as in our case, angiographic studies are normal.

J ALVAREZ-SABIN

J MONTALBÁN M TINTORE A CODINA

Department of Neurology, Hospital General Vall d'Hebron, Barcelona, Spain

Correspondence to: Dr Alvarez-Sabin, Rda San Antonio, 5 Ppal, 08011 Barcelona, Spain.

1 Azouvi $\mathrm{Ph}$, Tougeron $\mathrm{A}$, Hussonois $\mathrm{C}$ Schouman-Claeys E, Bussel B, Helkd JP. Pure sensory stroke due to midbrain haemorrhage limited to the spinothalamic pathway. $J$ Neurol Neurosurg Psychiatry 1989;52:1427-8.

2 Groothuis DR, Duncan GW, Fisher CM. The human thalamocortical sensory path in the human thalamocortical sensory path in the internal capsule. evidence from a small capsular haemorrhage causing a pure sensory
stroke. Ann Neurol 1977;2:328-31.
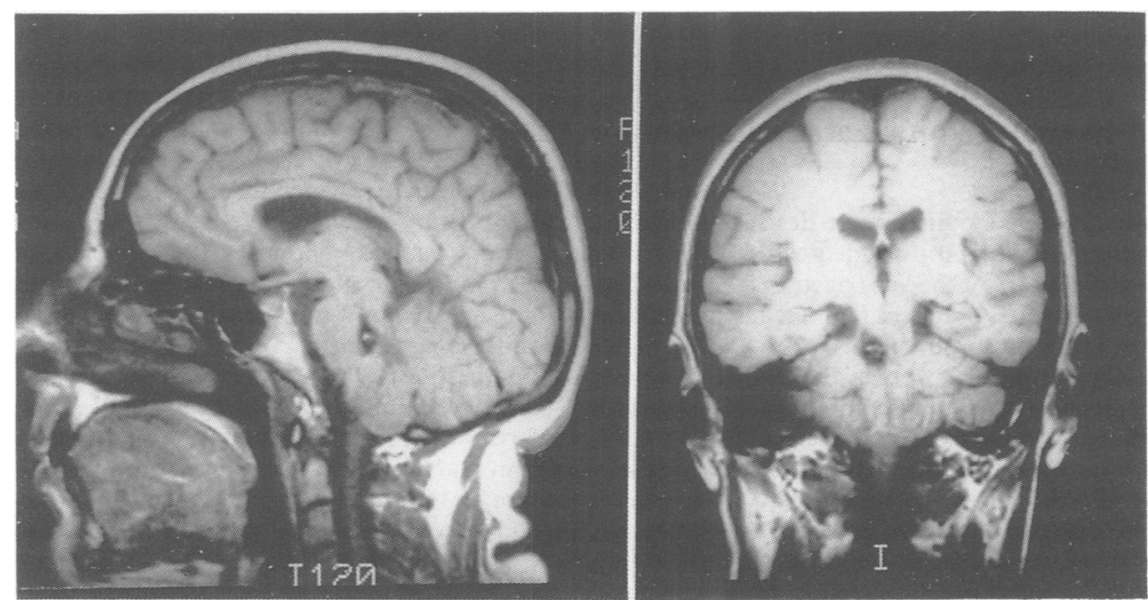

Figure Axial and sagittal $T_{1}$ MRI showing a cavernous angioma in the right dorsal part of the pons.

\section{Parkinsonism and defects of praxis following methanol poisoning}

The neurological sequelae of methanol intoxication shows marked individual variation, but Parkinsonism, optic atrophy and focal cranial nerve deficits have been described..$^{1-3} \mathrm{We}$ report a patient who presented with Parkinsonism and dyspraxia and who recovered from acute severe methanol poisoning. The MRI scan showed damage of the deep grey nuclei.

A 28 year old woman with a history of depression and recurrent alcohol abuse experienced nausea, vomiting, ataxia and blurred vision for 24 hours before she was admitted stuperose, with dilated pupils that did not react to light. The optic fundi were normal, and there were no localising neurological signs. The liver was enlarged. She had a leucocytosis of $12900 / \mathrm{mm}^{3}$ and a severe metabolic acidosis ( $\mathrm{pH} 7 \cdot 15$; bicarbonate $2.8 \mathrm{~m} \mathrm{Eq} / 1 ; \quad \mathrm{pO}_{2} 129 \mathrm{~mm} \mathrm{Hg} ; \quad \mathrm{pCO}_{2}$ $8 \mathrm{~mm} \mathrm{Hg}$ )

With the possibility of methanol poisoning in mind, she was given intravenous infusion of sodium bicarbonate and ethanol, and haemodialysis. The level of methanol in the blood was $2.85 \mathrm{~g} / \mathrm{l}$. After three hours, the acidosis was controlled. When the patient's level of consciousness improved, she admitted drinking some $200 \mathrm{ml}$ of methanol in the past 48 hours. She left the hospital after four days without apparent neurological or ocular abnormalities.

She was examined two years later, complaining of motor slowness and loss of memory. She had been working at the same factory at which she was employed before taking the methanol. The work required sequential and repetitive movements of both hands and feet. The employers stated that her productivity was reduced by $50 \%$.

Neurological examination showed a mild dysarthia, a Parkinsonian-like syndrome, with an expressionless face, limb bradykinesia, and abnormal postural reflexes. Rapid alternating finger movements were poorly performed. The glabella tap sign was positive and palmar-mental and peri-oral reflexes were present; her gait was characterised by poverty of associated movements, with reduced armswinging and body turning. The optic fundi displayed bitemporal pallor. Visual acuity was normal. Chest radiographs, ECG and EEG were normal. An unenhanced CT scan showed bilateral areas of decreased density, especially in the putamen. An MRI scan (fig) showed bilateral lesions involving the claus- 
trum, external capsule, putamen and head of the caudate nucleus. There was no evidence of cortical abnormality.

She was treated with clonazepam, pirazepam, madopar and bromocriptine, in various combinations, but she did not respond to treatment.

On a neuropsychological assessment, the patient was cooperative and well oriented. She complained of depression and difficulties with memory. The WAIS results were within the average range (Verbal IQ 104; Performance IQ 99). The Wechsler memory IQ was Low Average (MQ89). There was, however, some discrepancy on the results of the memory test. For instance, she recalled $9 / 24$ items of information in one of the prose passages, but only 4/23 in another. She had a poor digit span (four digits forwards, two digits backwards). Her score on paired associates was also poor. She scored $3 / 10$ on the first trial, and she did not improve with further presentations. On the other hand her ability to recall visual material was good and she made no errors on immediate recall. There was no evidence of specific language difficulties or other left hemisphere symptoms such as acalculia or constructional apraxia.

Because of her low productivity at work, and the fact that apraxia has been reported in patients with subcortical damage,${ }^{4}$ the patient was assessed with tests of motor skill and dyspraxia. She was slow, clumsy and lacked accuracy on three tests of motor skill requiring speed and accuracy of hand movements (Reitan-trial-making test, tracking test and tapping test). When performing these tests, she displayed a fine tremor of the left hand, which was not apparent on neurological examination. She was also asked to perform hand movement sequences and alternating movements of the left and right hand; her performance was distinctly inaccurate, and she was unable to improve after several trials.

Praxis evaluation was based on the performance of 20 meaningful gestures (for example, waving goodbye, using a comb) to command and imitation. She was also asked to imitate 10 meaningless hand/arm positions demonstrated by the examiner. In addition, she was asked to handle 10 single objects, and to perform more complex actions-on command and imitation-which required handling more than one object. She was also asked

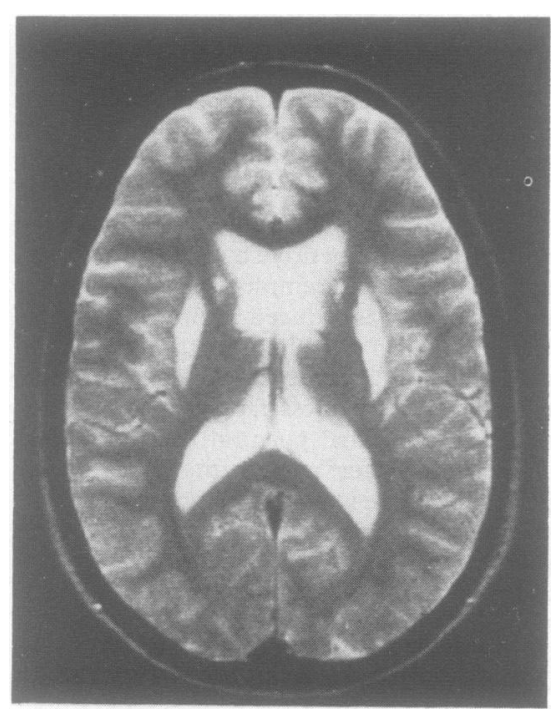

Figure Axial SE T2 weighted (TR $2400 \mathrm{~ms} / T E 90 \mathrm{~ms}$ ) image through mid lateral ventricular level (see text). to perform 10 facial gestures on command and imitation. Her performance on the tests requiring arm/hand movements was poor, and she made a number of errors similar to those seen in patients with apraxia.

She was unable to perform contralateral movements on imitation of meaningless postures. For instance, when asked to imitate a posture that required her to touch her left ear with the right hand, she touched her right ear with the right hand. She also made dyspraxic errors when handling real objects. Thus she took the comb by its teeth and attempted to comb her hair using the wrong side. She also attempted to strike a match with the wrong end. There was no evidence of oral apraxia.

This patient showed mild Parkinsonian features and, on tests of motor skill, she was slow, clumsy and inaccurate. In addition, there was a praxic impairment. The presence of praxic problems confirms the view that apraxia, usually considered a cortical sign, may also occur with lesions in the sub-cortical structures. This case is also interesting because the praxic problems did not result from an abrupt vascular accident, as in most previously reported cases.

Our findings support the view of De Renzi et $\mathrm{al}^{4}$ that the classical cortical lesions causing apraxia must be enlarged to encompass a basal ganglia-thalamus-cortex loop.

M J MOZAZ Faculty of Psychology, University of the Basque Country, San Sebastian, Spain Psychology Department Institute of Psychiatry London, UK B INDAKOETXEA Section of Neurology, Hospital Ntra Sra de Aranzazu San Sebastian, Spain

1 Guggenheim MA, Couch JR, Weinberg W. Motor dysfunction as a permanent complicaMotor dysfunction as a permanent complication of menth

2 McLean DR, Jacobs H, Mielke BW. Methanol poisoning: a clinical and pathological study Ann Neurol 1980;8:161-7.

3 Oliveras LC, Galindo GF. Parkinsonian syndrome after methanol intoxication. Eur Neuro 1983;22:405-9.

4 De Renzi E, Faglioni P, Scarpa M, Crisi G Limb apraxia in patient with damage confined to the left basal ganglia and thalamus. $J$ Neurol Neurosurg Psychiatry 1986;49:1030-8.

\section{Botulism with sensory symptoms: a second case}

In 1982 Goode and Shearn described a case of botulism with pinprick decreased sensation in the territory of the left trigeminal nerve. ${ }^{\prime}$ Our patient with botulism had left hemianalgesia of the body and the face.

A 43 year old woman developed vomiting and abdominal discomfort, with blurred vision, diplopia, dysphagia, dysphonia, dry mouth and numbness on the left side of her body and her face. She also had constipation and urine retention, that required bladder catheterisation. Six days before admission, she had ingested home-canned green beans. Her past medical history was unremarkable.

On neurological examination there were bilateral nonreactive mydriasis, ophthalmoplegia and ptosis, weakness of the soft palate and tongue with impairment of pharyngeal reflexes. She presented a decreased pinprick sensation on the left half of her body and her face. She had a mild diffuse global weakness. Reflexes were brisk and plantar responses flexor. Her skin and her mouth were dry. A Schirmer test was positive. A CT scan of the head and a CSF analysis were normal. Motor and sensory conduction velocities of the right ulnar nerve were normal. The $\mathrm{M}$-wave amplitudes were small $(1-3 \mathrm{mV})$ at sporadic stimulation, without any change at $2 \mathrm{~Hz}$ of repetitive stimulation, but at $30 \mathrm{~Hz}$ there was an increase of $183 \%$. There was also a moderate dysfunction of the autonomic nervous system assessed by standard tests. ${ }^{23}$ Blood pressure fell $24 \mathrm{~mm} \mathrm{Hg}$ (systolic) and $5 \mathrm{~mm} \mathrm{Hg}$ diastolic on standing. Heart rate response to standing: the ratio of the $R-R$ interval at beat 30 after standing to the $R-R$ interval at beat 15 after standing ${ }^{23}$ was 0.9 . Isometric exercise: the increase of diastolic $\mathrm{BP}$ was $6 \mathrm{~mm} \mathrm{Hg}$. Heart rate variation with respiration: the expiration/inspiration ratio was $1 \cdot 03$. The Valsalva ratio was $1 \cdot 05$. A serum specimen and a sample of the contaminated food were positive for type B botulinum toxin.

The patient's condition started to improve after five days. The left hemianalgesia disappeared on the sixth day and the hyperreflexia on the seventh day. She received botulinum trivalent antitoxin for three days after admission. Eighteen days later she developed a right acute suppurative parotitis, which resolved with antimicrobials and antiinflammatory agents. At discharge, one month after admission, she complained of a dry mouth and dry eyes. Two months later she was asymptomatic.

The clinical, neurophysiological ${ }^{4}$ and laboratory findings were consistent with a diagnosis of botulism, but the presence of sensory signs surprised the neurologists who examined the patient. The possibility of a stroke seemed unlikely since the patient had no risk factors, the symptoms developed concomitantly with the evolution of botulism, and a CT scan of the head was normal. The acute suppurative parotitis may have been related to a reduced production of saliva.

Botulinum toxin causes a marked reduction in the number of quanta released by a nerve stimulus. In vitro, at low doses, it blocks only cholinergic transmission and preferentially motor end-plates, but at high doses it may block other types of transmission. ${ }^{5}$

In the case reported by Goode and Shearn, the patient presented a hyperaesthesia on the left trigeminal territory, and they suggested that a multiple mononeuropathy could be underlying the clinical findings. Tendon reflexes were brisk, as was the case in our patient, a feature which is considered unusual in botulism.

Our patient showed impairment of neuromuscular and autonomic transmission. Only an impaired central transmission could probably explain her left pinprick hemihyperaesthesia, and therefore the possible presence of botulinum toxin within the CNS Most authors believe that a normal bloodbrain barrier function prevents botulinum toxin entering the brain tissue, but intraaxonal transport of radiolabelled toxin has been proved. ${ }^{6}$ Although we have no satisfactory explanation for sensory symptoms in our patient, we conclude, as do Goode and Shearn, that sensory abnormalities and 